\title{
Anne Herschberg-Pierrot, Jacques Neefs, dirs, Savoirs en récits
}

Vincennes, Presses universitaires de Vincennes, coll. Manuscrits modernes, 2010, vol. 1 et 2

\section{Christophe Ippolito}

\section{(2) OpenEdition}

\section{Journals}

Édition électronique

URL : http://journals.openedition.org/questionsdecommunication/2764

DOI : 10.4000/questionsdecommunication. 2764

ISSN : 2259-8901

Éditeur

Presses universitaires de Lorraine

Édition imprimée

Date de publication : 30 juin 2011

Pagination : 306-308

ISBN : 978-2-8143-0084-2

ISSN : 1633-5961

Référence électronique

Christophe Ippolito, "Anne Herschberg-Pierrot, Jacques Neefs, dirs, Savoirs en récits », Questions de communication [En ligne], 19 | 2011, mis en ligne le , consulté le 22 septembre 2020. URL : http:// journals.openedition.org/questionsdecommunication/2764; DOI : https://doi.org/10.4000/ questionsdecommunication.2764

Ce document a été généré automatiquement le 22 septembre 2020

Tous droits réservés 


\title{
Anne Herschberg-Pierrot, Jacques Neefs, dirs, Savoirs en récits
}

\author{
Vincennes, Presses universitaires de Vincennes, coll. Manuscrits \\ modernes, 2010, vol. 1 et 2
}

\section{Christophe Ippolito}

\section{RÉFÉRENCE}

Anne Herschberg-Pierrot, Jacques Neefs, dirs, Savoirs en récits. , Vincennes, Presses universitaires de Vincennes, coll. Manuscrits modernes, 2010, vol. 1 et 2, 192 p. et $176 \mathrm{p}$.

1 Ces deux volumes discutent l'usage que la littérature fait des savoirs au siècle des dictionnaires. Le premier, édité par Anne Herschberg-Pierrot, est exclusivement consacré à Gustave Flaubert, le second, édité par Jacques Neefs, s'ouvrant au-delà de Gustave Flaubert sur Honoré de Balzac, Gérard de Nerval, Jules Verne et les Goncourt. Le XIX ${ }^{\mathrm{e}}$ siècle fut celui de la modernité, du développement des savoirs et des croyances dans tous les domaines, et les deux éditeurs, qui préparent ensemble la nouvelle édition de Bouvard et Pécuchet pour la bibliothèque de la Pléiade, ont abondamment écrit sur les représentations que Gustave Flaubert en a faites. Comment les écrivains du temps jouent-ils de ces savoirs, comment les intègrent-t-ils à leurs œuvres ? Et quelles images en donnent-ils ? Voilà quelques-unes des questions auxquelles les contributeurs ont répondu. Notons d'emblée que les travaux ont le souci d'exposer en détail les croyances et les savoirs qu'ils analysent et que la critique des textes repose sur une connaissance solide des manuscrits et notes préparatoires des écrivains concernés, dans la lignée des préoccupations de la critique génétique. Un premier état de ces travaux a été présenté au séminaire Flaubert de l'Institut des textes et manuscrits modernes, et au colloque de Cerisy-la-Salle de 2006, « Flaubert, écrivain ».

2 La première contribution, qui risque une comparaison entre la "main invisible » d'Adam Smith et l'impersonnalité de Gustave Flaubert, montre comment, dans une 
société qui a peur du libéralisme économique, Gustave Flaubert, inspiré par Frédéric Bastiat et Richard Cobden, tranche en célébrant le traité de libre-échange avec l'Angleterre en 1860 (Françoise Mélonio, 1: 15-33). Ses critiques s'exercent contre l'orthodoxie d'où qu'elle vienne. Parmi ses « haines », figurent la mainmise de l'État sur l'économie, celle de la religion sur la société, mais aussi le socialisme, les foules (ce qu'il appelle le «On»), le suffrage universel, le parlementarisme, l'autorité et l'idolâtrie (après Benjamin Constant), les doctrinaires (François Guizot, Victor Cousin, Pierre-Paul Royer-Collard, etc.), et tout ce qui peut dégrader la liberté individuelle. Plusieurs contributions montrent comment Salammbô déconstruit et reconstruit l'histoire antique et contemporaine (car le livre joue comme on sait sur le parallèle). Du côté de l'écriture de l'histoire, dans ce livre antimoderne qui est aussi une méditation sur la décadence, Gustave Flaubert apparait comme un historien de la longue durée, qui s'imprègne de l'archéologie naissante, et s'interroge sur la réalité de la culture antique chez ses contemporains (Nicolas Bourguinat, 1:35-61). On ne peut le séparer des historiens qui, en 1860, utilisaient encore des textes littéraires, et des essayistes qui, dans la lignée de Jules Michelet, mettaient en avant faculté d'invention et démarche affective. Sous la fiction transparaissent en filigrane des essais de synthèse sur l'impérialisme, ou sur le rapport entre le «Barbare » et le civilisé. Mais c'est bien le problème des preuves qui est au centre du livre; Salammbô refuse le finalisme et le causalisme de l'histoire et développe le discours de la légende, le merveilleux et l'effet de monde (Gisèle Séginger, $1: 63-85$ ). Par ailleurs, si Gustave Flaubert a choisi un conflit marginal des guerres puniques, ce qui lui permet d'échapper à l'historicité de l'histoire, cela ne l'empêche pas d'assouvir sa passion documentaire par le dépeçage de plusieurs sources érudites, dont le Banquet des savants d'Athénée, dépeçage qu'examine en détail une contribution soulignant notamment l'écart entre le savoir accumulé pour Salammbô et la représentation de ceux qui n'ont pas accès à ce savoir, les «Barbares » (Agnès Bouvier, 2 : 93-102). Dans le champ artistique, Gustave Flaubert critique durement les tenants de l'histoire littéraire, d'Abel-François Villemain à Saint-René Taillandier qui voulaient remplacer la rhétorique par leur agenda et leurs discours normés (et notamment une critique morale que Gustave Flaubert ne supportait guère). Le champ constitué autour de l'équipe de la Revue des deux mondes, de Charles-Augustin SainteBeuve à Jean-Jacques Ampère, de Saint-Marc Girardin à Désiré Nisard, d'Alfred-Auguste Cuvillier-Fleury à Hippolyte Taine, engendre des luttes pour un pouvoir littéraire institutionnel que Gustave Flaubert ridiculise (Marie-Ève Thérenty, 1: 110-143). Les conceptions que ces nouveaux notables défendent, du biographisme à l'explication par la race, le milieu ou le moment, sont totalement étrangères à l'esthétisme et à l'impersonnalité flaubertiens.

3 Cet esthétisme est aussi examiné du point de vue de la muséographie (Pierre-Marc de Biasi, $1: 145-162)$. Gustave Flaubert, contemporain de la mise en place des musées (relativement tardive en France), grand amateur de musées lui-même (il célèbre notamment le Musée de Cluny, l'Hôtel Carnavalet et le cabinet des médailles de la Bibliothèque nationale) et, particulièrement, des musées en plein air que sont les sites archéologiques, critique l'arrachement des œuvres d'art à leur contexte originel, et la constitution de collections privées. Ses calepins et carnets de voyage contiennent des indications précieuses aussi bien par leur méthode que par leur contenu. Est également examiné un champ bien labouré, celui de l'art industriel, de la reproduction et du faux dans L'Éducation sentimentale (Nicole Savy, 1 : 163-177). 
Plusieurs contributions concernent la religion et ses discours. Chez Nerval (JeanNicolas Illouz, $2: 49-69$ ), sont étudiés la mélancolie liée à la passion de savoir, la résurgence du religieux dans le politique autour de 1848, la tolérance (dans le Voyage en Orient), le lien entre savoir et religions dans Les Illuminés, la tentation du paganisme et le syncrétisme des "Mémorables" dans Aurélia. Deux contributions sur Hérodias examinant notamment, au-delà des modèles pour Salomé, la littérarisation du mythe biblique et le problème de la diffusion du christianisme, font la différence entre un savoir documentaire et un savoir critique, du côté de l'interprétation (Bertrand Marchal, 2: 71-84 ; Cécile Matthey, 2: 85-92). Parmi les problèmes posés figurent l'accueil réservé au divin et l'interprétation du mystère de l'Incarnation. Plus largement, l'utilisation humaine du divin dans les Trois Contes et d'autres œuvres de Gustave Flaubert fait l'objet d'analyses approfondies. Un travail sur Saint Julien l'hospitalier est l'occasion d'évaluer l'appropriation ludique du savoir sur le merveilleux médiéval, la philologie naissante, et la médecine du temps, et ce par le truchement d'un ami de Gustave Flaubert, Alfred Maury. Ce dernier a contribué à une critique raisonnée du merveilleux dans son Essai sur les légendes pieuses au moyen-âge, et fut aussi l'auteur de théories sur les rêves et les hallucinations exposées dans un livre intitulé Le Sommeil et les rêves, théories utilement commentées ici (Florence Vatan, 1: 87-107). Une contribution examine les pratiques de voyage et d'écriture de Gustave Flaubert en Orient (par opposition à celles de Maxime Du Camp) et analyse des expériences esthétiques et spirituelles dans le désert ou sur la mort (Sarga Moussa, 2 : 103-118).

Parmi les auteurs également présentés, figure Honoré de Balzac (Stéphane Vachon, 2 : 15-48), qui avait projeté de faire suivre la Comédie humaine d'un Essai sur les forces humaines. Dès le début, Honoré de Balzac est intéressé par tous les savoirs : vrais, faux, intermédiaires, théoriques (ainsi lorsqu'il rend compte de la querelle de 1830 entre Georges Cuvier et Étienne Geoffroy Saint-Hilaire), mais aussi pratiques. L'anatomie, la chimie, et les rapports entre homme, animal et environnement informent ses œuvres. S'interroger sur son rapport au savoir, c'est aussi se demander dans quelle mesure la source documentaire peut valider l'invention de la vérité esthétique. Une contribution sur L'île mystérieuse de Jules Verne (Jacques Noiray, 2 : 119-138) présente l'ambition de l'auteur et de son éditeur Pierre-Jules Hetzel (résumer les connaissances amassées par la science moderne) pour cette robinsonnade où s'accumulent les descriptions didactiques (du minerai de fer aux variétés de singes) et où différents types de connaissances sont convoqués et évalués. Le souci de la causalité n'empêche pas l'ouverture au mystère. Ainsi les figures de l'ingénieur Cyrus Smith et de Nemo, emblématiques d'une techné victorieuse, ouvrent-elles aussi une réflexion sur la difficulté de la définition de l'homme. Une contribution sur le Journal des Goncourt (Jean-Louis Cabanès, $2: 139-163$ ) insiste sur la valeur des documentaires « intimes » et « humains » et sur la sociologie des lettres que les deux frères initient. Dans le Journal, Edmond et Jules de Goncourt métamorphosent les savoirs, rendant littéraire ce qui ne l'était pas à l'origine. Cette métamorphose est au cœur de ce collectif, qui ouvre une nouvelle série de la collection "Manuscrits modernes", série qui s'attachera "aux modes d'invention, aux croisements de savoirs, de questions, de disciplines, dont les œuvres sont le lieu». 


\section{AUTEURS}

\section{CHRISTOPHE IPPOLITO}

Georgia Institute of Technology

Écritures, université Paul Verlaine-Metz 